\title{
Effect of pravastatin on erythrocyte membrane fatty acid contents in patients with chronic kidney disease
}

\author{
Su Mi Lee ${ }^{1}$, Young Ki Son ${ }^{1}$, Seong Eun $\mathrm{Kim}^{1}$, Yeong Hoon $\mathrm{Kim}^{2}$, Yongsoon Park ${ }^{3}$, Won Suk An ${ }^{1}$ \\ ${ }^{1}$ Department of Internal Medicine, Dong-A University, Busan, Republic of Korea \\ ${ }^{2}$ Department of Internal Medicine, Inje University Busan Paik Hospital, Busan, Republic of Korea \\ ${ }^{3}$ Department of Food and Nutrition, Hanyang University, Seoul, Republic of Korea
}

Background: Statin treatment has decreased the risk of cardiovascular events in patients with chronic kidney disease (CKD). Erythrocyte membrane oleic acid level is higher in patients with acute coronary syndrome. This study aimed to evaluate the effect of pravastatin on the erythrocyte membrane fatty acid (FA) contents in patients with CKD.

Methods: Sixty-two patients were enrolled from January 2017 to March 2019 (NCTO2992548). Pravastatin was initially administered at a dose of $20 \mathrm{mg}$ for 24 weeks. The pravastatin dose was increased to $40 \mathrm{mg}$ after 12 weeks if it was necessary to control dyslipidemia. The primary outcome was change in erythrocyte membrane FA, including oleic acid, after pravastatin treatment for 24 weeks.

Results: Forty-five patients finished this study, and there was no adverse effect related to pravastatin. Compared with baseline, total cholesterol and low-density lipoprotein cholesterol levels were significantly decreased after pravastatin treatment. Compared with baseline, saturated FA, oleic acid, and arachidonic acid levels were significantly increased and polyunsaturated FA and linoleic acid (LA) levels were significantly decreased after pravastatin treatment. There was also a decrease in eicosapentaenoic acid after pravastatin treatment in CKD patients with estimated glomerular filtration rate $<60 \mathrm{~mL} / \mathrm{min} / 1.73 \mathrm{~m}^{2}$.

Conclusion: Administration of pravastatin in patients with CKD leads to a decrease in FA known to be protective against the risk of CVD. Omega-3 FA or LA supplementation might be necessary to recover changes in erythrocyte membrane FA contents when pravastatin is used for treating dyslipidemia in patients with CKD.

Keywords: Chronic kidney disease, Omega-3 fatty acid, Pravastatin

\section{Introduction}

The mortality rate in patients with chronic kidney disease (CKD) increases with a decrement of kidney function and presence of cardiovascular disease (CVD), and this is a ma- jor cause of morbidity in patients with CKD. According to the United States Renal Data System, patients with CKD experienced higher mortality rates of 111.2 per 1,000 patient-years than the general population, at 45.2 per 1,000 in 2014 . In particular, the mortality rate is higher in patients with CKD

Received: December 4, 2020; Revised: February 22, 2021; Accepted: March 21, 2021

Editor: Hyo Wook Gil, Soonchunhyang University, Cheonan, Republic of Korea

Correspondence: Won Suk An

Department of Internal Medicine, Dong-A University Hospital, 26 Daesingongwon-ro, Seo-gu, Busan 49201, Republic of Korea.

E-mail: anws@dau.ac.kr

ORCID: https://orcid.org/0000-0003-4015-0284

Copyright (C) 2021 by The Korean Society of Nephrology

(a) This is an Open Access article distributed under the terms of the Creative Commons Attribution Non-Commercial and No Derivatives License (http:// creativecommons.org/licenses/by-nc-nd/4.0/) which permits unrestricted non-commercial use, distribution of the material without any modifications, and reproduction in any medium, provided the original works properly cited. 
having diabetes mellitus (DM) than in those with DM alone [1]. This is because there are nontraditional risk factors such as insulin resistance, malnutrition, mineral bone disorders, and traditional risk factors inducing cardiovascular complications such as dyslipidemia, smoking, and obesity in CKD [2]. Some patients with CKD die of CVD before need for dialysis [3].

Treatment with the statins class of drugs has decreased the risk of CVD in patients with CKD. The Kidney Disease: Improving Global Outcomes guideline recommend the use of statin drugs in predialysis patients [4]. The effect of statins is attributed to a decrease in low-density lipoprotein (LDL)-cholesterol, sometimes accompanied by an increase in high-density lipoprotein (HDL)-cholesterol and a decrease in triglycerides. Recent clinical trials have shown that drugs, such as fibrate or nicotinic acid, that increase HDL-cholesterol or reduce triglycerides are not recommended in patients with CKD owing to safety or toxicity concerns $[4,5]$. In particular, if statins are used effectively, there are no additional benefits of those drugs to the incidence of CVD or mortality $[6,7]$. This suggests that treatment with statins is sufficient to achieve the same effects as use of nicotinic acid or fibrate.

Omega-3 fatty acid (FA) is known to reduce the incidence of CVD, especially myocardial infarction or arrhythmia, in such drug-naive patients [8,9]. This FA is associated with anti-inflammatory, anti-thrombotic, and antioxidant effects. As statins also have anti-inflammatory and antioxidant effects [10,11], it is postulated that the cardioprotective effects of omega-3 FA can be achieved by statin treatment alone. However, there are no reports on the effect of statins on erythrocyte membrane FA contents in patients with CKD. Erythrocyte membrane FA contents is not affected by temporary dietary changes and reflect the dietary FA contents within 3 months [12]. The omega-3 index, which represents the sum of eicosapentaenoic acid (EPA) and docosahexaenoic acid (DHA) contents in the erythrocyte membrane, is a risk factor of death from CVD [13]. This study aimed to evaluate the effect of pravastatin on erythrocyte membrane FA contents in patients with CKD.

\section{Methods}

\section{Study design and patients}

We performed a single-arm prospective clinical trial at two centers between January 2017 and March 2019 (NCT 02992548). Sixty-two patients who were treated for CKD not requiring dialysis were included. The exclusion criteria were history of statins, fish oil, or omega-FA supplementation within 3 months; history of fish, gelatin, and/or omega-3 FA allergies; history of hospital admission caused by CVD, infection, or acute kidney injury within 3 months; dyslipidemia caused by nephrotic syndrome; use of contrast within 2 weeks; albumin level $<3.0 \mathrm{~g} / \mathrm{dL}$; and malignancy and/or liver cirrhosis. After exclusion of patients, 45 patients completed this study.

Pravastatin was prescribed for patients with LDL-cholesterol of $>100 \mathrm{mg} / \mathrm{dL}$ and with coronary artery disease or equivalent risk factors (peripheral artery disease, abdominal aneurysm, carotid artery disease, or DM); patients with LDL-cholesterol of $>130 \mathrm{mg} / \mathrm{dL}$ and with two or more cardiovascular risk factors; and patients with LDL-cholesterol of $>160 \mathrm{mg} / \mathrm{dL}$. Pravastatin was administered initially at dose of $20 \mathrm{mg}$ for 24 weeks. The pravastatin dose was increased to 40 $\mathrm{mg}$ after 12 weeks if it was necessary to control dyslipidemia. Subjects were divided into $\geq 60$ or $<60$ estimated glomerular filtration rate (eGFR, $\mathrm{mL} / \mathrm{min} / 1.73 \mathrm{~m}^{2}$ ).

The primary outcome of this study was change in erythrocyte membrane FA, including oleic acid, after pravastatin treatment for 24 weeks. We measured total cholesterol, triglycerides, LDL-cholesterol, HDL-cholesterol, and adiponectin levels as secondary outcomes at baseline and at 24 weeks.

Informed consent was obtained from all enrolled patients. The study was approved by the Dong-A University and Inje University Hospital Institutional Review Boards (No. 15038). This study was conducted according to the Helsinki Declaration.

\section{Biochemical and hematologic evaluation}

Blood samples were obtained, processed, refrigerated, and stored at $-70^{\circ} \mathrm{C}$ until analysis. Serum hemoglobin, glucose, blood urea nitrogen, creatinine ( $\mathrm{sCr}$ ), albumin, cystatin $\mathrm{C}$, C-reactive protein (CRP), total cholesterol, triglycerides, LDL-cholesterol, and HDL-cholesterol levels were analyzed. Adiponectin level was measured using enzyme-linked immunoassay (BioVendor Laboratory Medicine, Modrice, Czech Republic).

\section{Gas chromatography}

Erythrocyte membrane FA contents were measured us- 
ing gas chromatography at baseline and at 24 weeks using methods reported previously $[14,15]$. The omega-3 index is a measure of EPA and DHA in erythrocyte membranes [13]. Erythrocyte membrane FA contents are expressed as a weight percentage of total FA.

\section{Statistics}

We calculated that a sample size of 31 patients per group was needed to achieve at least $80 \%$ power to detect an effective mean difference in erythrocyte membrane oleic acid content of $2.5 \pm 2.0$ weight $\%$ at a two-sided significance level of 0.05 and assuming a dropout rate of $20 \%$ [14]. Sixty-two participants were divided into two groups of 31 participants based on eGFR and analyzed.

The data are presented as means \pm standard deviations or frequencies. The characteristics were analyzed using the Mann-Whitney U test or Wilcoxon exact rank sum test for nonparametric data and the chi-square test for categorical variables. All analyses were performed using PASW Statistics version 18.0 (IBM Corp., Armonk, NY, USA). A p-value of $<0.05$ was considered statistically significant.

\section{Results}

\section{Baseline characteristics}

Forty-five patients completed this study. As shown in Table 1, the average age of the patients was $59.2 \pm 12.4$ years, $42.2 \%$ were male patients, and $48.9 \%$ had DM. The mean systolic and diastolic blood pressure readings were $132.6 \pm 24.7$ and $72.6 \pm 13.1 \mathrm{mmHg}$, respectively. Baseline $\mathrm{sCr}$ was $1.5 \pm 0.7$ $\mathrm{mg} / \mathrm{dL}$, and eGFR was $54.2 \pm 27.3 \mathrm{~mL} / \mathrm{min} / 1.73 \mathrm{~m}^{2}$. All patients were treated with an initial dose of $20 \mathrm{mg}$ pravastatin for 24 weeks. The pravastatin dose was increased to $40 \mathrm{mg}$ after 12 weeks in five patients.

\section{Changes in biochemical data}

Compared with baseline, total cholesterol, LDL-cholesterol, and CRP levels were significantly decreased after pravastatin treatment (Table 1). There were no significant changes in triglycerides, HDL-cholesterol, $\mathrm{sCr}$, amount of proteinuria, and adiponectin levels.

\section{Changes in erythrocyte membrane fatty acid content}

As shown in Table 2 and Fig. 1, the erythrocyte membrane contents of saturated FA (SFA), stearic acid, lignoceric acid, oleic acid, and arachidonic acid (AA) were significantly increased after pravastatin treatment compared with baseline ( $\mathrm{p}=0.04, \mathrm{p}=0.006, \mathrm{p}=0.02, \mathrm{p}=0.006$, and $\mathrm{p}<0.001$, respectively). The erythrocyte membrane contents of polyunsaturated FA (PUFA) and linoleic acid (LA) were significantly decreased after pravastatin treatment compared with baseline ( $\mathrm{p}=0.001, \mathrm{p}=0.001$, respectively). The erythrocyte membrane contents of EPA and the omega-3 index tended to decrease after pravastatin treatment, although these changes were not statistically significant $(\mathrm{p}=0.07, \mathrm{p}=0.09$, respectively).

\section{Changes in biochemical and erythrocyte membrane fatty acid contents according to kidney function}

Participants were divided into two groups of $\geq 60$ and $<60$ $\mathrm{mL} / \mathrm{min} / 1.73 \mathrm{~m}^{2}$ eGFR level. The total cholesterol and LDL-cholesterol levels decreased after pravastatin use regardless of kidney function. The erythrocyte membrane FA contents at baseline showed no significant difference between the two groups (Table 3). In patients with eGFR of $<60 \mathrm{~mL} / \mathrm{min} / 1.73 \mathrm{~m}^{2}$, the erythrocyte membrane contents of SFA, monounsaturated FA, and oleic acid were significantly increased after 24 weeks compared with baseline ( $p=0.04$, $\mathrm{p}=0.04$, and $\mathrm{p}=0.006$, respectively, Table 3 ). Compared with baseline, the erythrocyte membrane contents of PUFA, LA, and EPA were significantly decreased after pravastatin treatment in patients with eGFR of $<60 \mathrm{~mL} / \mathrm{min} / 1.73 \mathrm{~m}^{2}$ (p $<0.001, \mathrm{p}=0.008$, and $\mathrm{p}=0.04$, respectively, Fig. 2). Erythrocyte membrane content of AA was significantly increased after pravastatin treatment in both groups $(p=0.009$ in patients with eGFR of $\geq 60 \mathrm{~mL} / \mathrm{min} / 1.73 \mathrm{~m}^{2}$ and $\mathrm{p}=0.01$ in those with eGFR of $<60 \mathrm{~mL} / \mathrm{min} / 1.73 \mathrm{~m}^{2}$ ). The erythrocyte membrane omega-3 index was decreased in both groups after 24 weeks compared with baseline, although this was not statistically significant $(\mathrm{p}=0.72$ in patients with eGFR of $\geq 60 \mathrm{~mL} / \mathrm{min} / 1.73 \mathrm{~m}^{2}$ and $\mathrm{p}=0.07 \mathrm{in}$ those with eGFR of $<60$ $\mathrm{mL} / \mathrm{min} / 1.73 \mathrm{~m}^{2}$ ).

\section{Adverse effects and dropout}

There were no adverse effects related to pravastatin treatment. Six patients refused final sampling, three patients dropped out, and blood samples of four patients were lost. 
Table 1. Clinical blood biochemical analyses of the subjects

\begin{tabular}{|c|c|c|c|}
\hline Characteristic & Baselin & At 24 weeks & p-value \\
\hline No. of patients & 45 & 45 & \\
\hline Age (yr) & $59.2 \pm 12.4$ & & \\
\hline Male sex & $19(42.2)$ & & \\
\hline Diabetes mellitus & 22 (48.9) & & \\
\hline Systolic BP (mmHg) & $132.6 \pm 24.7$ & $124.4 \pm 21.3$ & $0.04 *$ \\
\hline Diastolic BP (mmHg) & $72.6 \pm 13.1$ & $68.2 \pm 14.1$ & 0.11 \\
\hline Calcium (mg/dL) & $9.3 \pm 0.5$ & $9.1 \pm 0.5$ & 0.05 \\
\hline Phosphorus (mg/dL) & $3.8 \pm 0.5$ & $3.8 \pm 0.6$ & 0.83 \\
\hline Glucose (mg/dL) & $123.8 \pm 33.2$ & $120.3 \pm 29.6$ & 0.63 \\
\hline BUN (mg/dL) & $24.2 \pm 12.5$ & $24.5 \pm 13.8$ & 0.78 \\
\hline Creatinine (mg/L) & $1.5 \pm 0.7$ & $1.6 \pm 0.9$ & 0.20 \\
\hline $\begin{array}{l}\text { GFR } \\
\left(\mathrm{mL} / \mathrm{min} / 1.73 \mathrm{~m}^{2}\right)\end{array}$ & $54.2 \pm 27.3$ & $54.1 \pm 30.2$ & 0.38 \\
\hline Cystatin C (mg/dL) & $1.8 \pm 0.7$ & $1.8 \pm 0.8$ & 0.52 \\
\hline Uric acid (mg/dL) & $6.7 \pm 1.8$ & $6.6 \pm 1.7$ & 0.38 \\
\hline $\begin{array}{l}\text { Total cholesterol } \\
(\mathrm{mg} / \mathrm{dL})\end{array}$ & $223.1 \pm 50.8$ & $168.4 \pm 32.5$ & $<0.001 *$ \\
\hline Albumin (g/dL) & $4.2 \pm 0.3$ & $4.3 \pm 0.3$ & 0.11 \\
\hline AST (U/L) & $27.5 \pm 11.0$ & $25.7 \pm 8.7$ & 0.33 \\
\hline ALT (U/L) & $28.4 \pm 40.0$ & $22.5 \pm 12.0$ & 0.65 \\
\hline Triglycerides (mg/dL) & $185.7 \pm 111.8$ & $159.2 \pm 85.5$ & 0.40 \\
\hline $\begin{array}{l}\text { HDL-cholesterol } \\
\text { (mg/dL) }\end{array}$ & $50.0 \pm 18.2$ & $46.8 \pm 15.4$ & 0.26 \\
\hline $\begin{array}{l}\text { LDL-cholesterol } \\
\text { (mg/dL) }\end{array}$ & $149.1 \pm 35.3$ & $100.1 \pm 25.4$ & $<0.001 *$ \\
\hline CRP (mg/dL) & $0.4 \pm 0.4$ & $0.2 \pm 0.2$ & $0.04 *$ \\
\hline Urine protein (g/g) & $1.3 \pm 2.0$ & $1.6 \pm 3.5$ & 0.39 \\
\hline HbA1c (\%) & $6.5 \pm 1.0$ & $6.7 \pm 1.2$ & 0.24 \\
\hline Adiponectin $(\mu \mathrm{g} / \mathrm{mL})$ & $8.8 \pm 4.3$ & $8.9 \pm 4.9$ & 0.57 \\
\hline
\end{tabular}

Data are expressed as number only, mean \pm standard deviation, or number (\%).

ALT, alanine aminotransaminase; AST, aspartate aminotransferase; $\mathrm{BP}$, blood pressure; BUN, blood urea nitrogen; CRP, C-reactive protein; $\mathrm{DM}$, diabetes mellitus; GFR, glomerular filtrate rate; $\mathrm{HbA1c}$, glycosylated hemoglobin; HDL-cholesterol, high-density lipoprotein cholesterol; LDLcholesterol, low-density lipoprotein cholesterol.

The nonparametric Wilcoxon exact rank sum test was used to compare baseline data with 24 -weeks data; ${ }^{*} p<0.05$ (mean values are significantly different from baseline).

Four patients were withdrawn from analysis because of acute kidney injury not related to pravastatin. No hepatic dysfunction was found during the course of the study.

\section{Discussion}

In this single-arm prospective study, 24 weeks-administration of pravastatin reduced total cholesterol and LDL-cholesterol in patients with CKD. In contrast, erythrocyte
Table 2. Changes of erythrocyte membrane fatty acid contents after pravastatin treatment

\begin{tabular}{lrrl}
\hline Variable & $\begin{array}{r}\text { Baseline } \\
(\mathrm{n}=45)\end{array}$ & $\begin{array}{c}\text { At } 24 \text { weeks } \\
(\mathrm{n}=45)\end{array}$ & p-value \\
\hline Saturated & $40.4 \pm 1.4$ & $40.6 \pm 1.2$ & $0.04^{*}$ \\
Myristic & $0.3 \pm 0.1$ & $0.3 \pm 0.1$ & 0.12 \\
Palmitic & $23.2 \pm 1.4$ & $23.0 \pm 1.3$ & 0.52 \\
Stearic & $16.4 \pm 0.9$ & $16.8 \pm 1.0$ & $0.006^{*}$ \\
Lignoceric & $0.5 \pm 0.2$ & $0.4 \pm 0.1$ & $0.02^{*}$ \\
Monounsaturated & $15.8 \pm 1.1$ & $16.2 \pm 1.2$ & 0.08 \\
Palmitoleic & $0.6 \pm 0.3$ & $0.5 \pm 0.3$ & 0.22 \\
Trans-oleic & $0.3 \pm 0.1$ & $0.4 \pm 0.1$ & 0.35 \\
Oleic & $14.7 \pm 1.0$ & $15.2 \pm 1.0$ & $0.006 *$ \\
Polyunsaturated & $42.8 \pm 1.8$ & $42.3 \pm 1.6$ & $0.001^{*}$ \\
Omega-6 & $29.0 \pm 3.0$ & $28.8 \pm 2.7$ & 0.46 \\
Linoleic & $11.7 \pm 2.4$ & $10.7 \pm 2.2$ & $0.001^{*}$ \\
AA & $13.1 \pm 2.0$ & $13.6 \pm 1.9$ & $<0.001^{*}$ \\
Omega-3 & $13.8 \pm 2.9$ & $13.5 \pm 2.7$ & 0.20 \\
Alpha-linolenic & $0.3 \pm 0.2$ & $0.3 \pm 0.2$ & 0.19 \\
EPA & $2.0 \pm 1.1$ & $1.9 \pm 1.0$ & 0.07 \\
DHA & $8.8 \pm 1.7$ & $8.6 \pm 1.5$ & 0.15 \\
Omega-3 index & $10.9 \pm 2.5$ & $10.5 \pm 2.3$ & 0.09 \\
AA/EPA & $9.7 \pm 9.5$ & $10.5 \pm 8.5$ & 0.12 \\
Omega-6/omega-3 & $2.2 \pm 0.7$ & $2.3 \pm 0.7$ & 0.60 \\
\hline Data are exprssed & & &
\end{tabular}

Data are expressed as mean \pm standard deviation; erythrocyte membrane fatty acid content is expressed as a weight percentage of total fatty acid.

AA, arachidonic acid; DHA, docosahexaenoic acid; EPA, eicosapentaenoic acid.

The nonparametric Wilcoxon exact rank sum test was used to compare baseline data with 24-weeks data; ${ }^{*} \mathrm{p}<0.05$ (mean values are significantly different from baseline).

membrane level of oleic acid was increased by pravastatin treatment. Erythrocyte membrane level of oleic acid is significantly higher in patients with acute coronary syndrome and undergoing dialysis than in control subjects $[16,17]$. Therefore, increased oleic acid level after pravastatin use reflects harmful cardiovascular outcome. Statins are approved as a standard therapy for patients with dyslipidemia because of their potent effects of controlling lipid levels and preventing cardiovascular events. In this study, the percentage reduction in average LDL-cholesterol level was $32.9 \%$, and it is expected that lowered LDL-cholesterol level resulted in fewer cardiovascular complications. However, there were unexpected changes in oleic acid level in patients with CKD using pravastatin. In addition, it might be necessary to investigate the clinical outcomes and mechanisms responsible for the change in oleic acid level.

The important pleiotropic effect of statins is anti-inflammatory. Pravastatin therapy produced an anti-inflammatory effect 


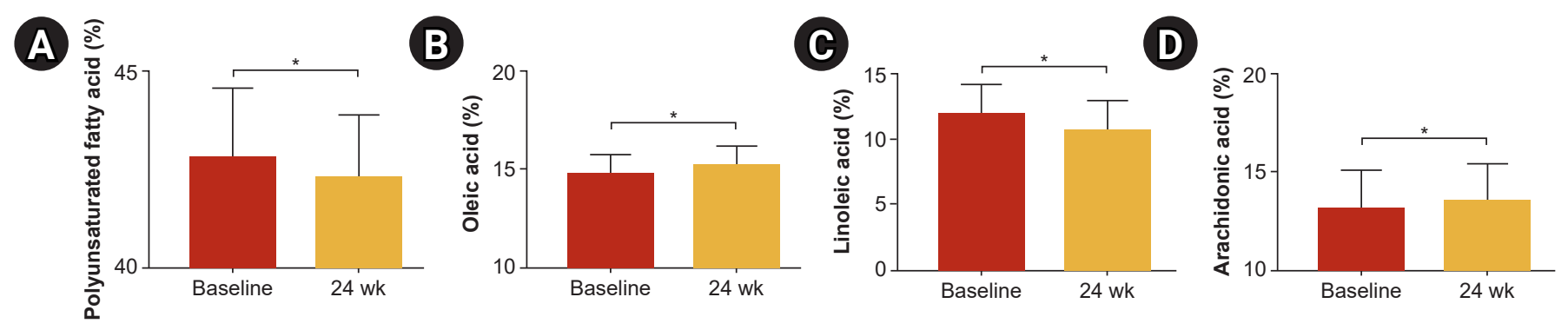

Figure 1. Changes of erythrocyte membrane fatty acid after pravastatin treatment. (A) Polyunsaturated fatty acid, (B) oleic acid, (C) linoleic acid, and (D) arachidonic acid in erythrocyte membrane.

$\star p<0.05$ (mean values are significantly different from baseline).

by decreasing CRP in patients with CKD in this study. However, erythrocyte membrane level of AA was increased by pravastatin treatment, which can induce inflammatory mediators and is associated with inflammation. For erythrocyte membrane FA contents, anti-inflammatory strategies are necessary for augmenting the anti-inflammatory effect of pravastatin. The distribution degree of omega-3 FA, such as EPA and DHA, and the omega-3 index are well-known major risk factors of CVD $[13,18]$. Omega-3 FA supplementation, which produces an anti-inflammatory effect, can lower the risk of inflammation caused by increased AA.

Decreased erythrocyte membrane LA level is related to DM prevalence [19]. Previous studies have reported a relationship between use of statins and increased risk of DM $[20,21]$. Therefore, supplementation of LA is important to reduce possible risk of DM, especially in patients with CKD. In a previous study, erythrocyte membrane EPA and DHA levels were significantly increased in patients with diabetic nephropathy after omega-3 FA use [22]. A study reporting a decrease in erythrocyte membrane oleic acid level after omega-3 FA suggests that the cardioprotective effect of omega-3 FA in dialysis patients is related to modulation of erythrocyte membrane FA contents [14]. These studies suggest that additional supplementation with PUFA can be helpful to correct changes that occur in erythrocyte membrane FA contents, including oleic acid and LA, after pravastatin use. Our study provides additional information to attend to erythrocyte membrane FA during statin use in patients with CKD. Additional studies are necessary to support the possible risks of using statins in patients with CKD.

Some studies suggest that combination therapy with statins and omega-3 FA did not show an additional decrease in cardiovascular events compared with therapy with statins alone $[6,7,23]$. Whether administration of omega-3 FA in addition to statins is effective in preventing CVD remains controversial; however, triglyceride lowering treatment is effective in preventing CVD [9]. Additional administration of omega-3 FA might help patients with hypertriglyceridemia because of its potent effect on triglyceride levels [24]. In addition, the beneficial effects of statins on the lipid profile and their effects on the erythrocyte membrane FA contents are not known. This is the first study assessing changes in erythrocyte membrane FA contents after statin treatment in patients with CKD. Based on our data, there was a decrease in EPA level and an increase in oleic acid level after pravastatin treatment, especially in patients with eGFR of $<60 \mathrm{~mL} /$ $\min / 1.73 \mathrm{~m}^{2}$. Therefore, we recommend that the changes in erythrocyte membrane FA contents after pravastatin treatment can be recovered by co-supplementation with omega-3 FA, especially in patients with eGFR of $<60 \mathrm{~mL} /$ $\mathrm{min} / 1.73 \mathrm{~m}^{2}$. There was no significant decrease in EPA level or increase in oleic acid level after pravastatin treatment in patients with eGFR of $>60 \mathrm{~mL} / \mathrm{min} / 1.73 \mathrm{~m}^{2}$. We assume that these nonsignificant changes in patients with eGFR of $>60$ $\mathrm{mL} / \mathrm{min} / 1.73 \mathrm{~m}^{2}$ are related with high dropout rate and relatively higher EPA level compared to patients with eGFR of $<60 \mathrm{~mL} / \mathrm{min} / 1.73 \mathrm{~m}^{2}$.

The first treatment in patients with dyslipidemia is lifestyle modification, including dietary education. Dietary guidelines, including the American College of Cardiology/ American Heart Association Cholesterol Guideline [25] and the Dietary Reference Intake for Koreans [26], emphasize the quality and quantity of dietary fat. The guidelines recommend restricting SFA intake to $<7 \%$ and trans-FA intake to $<1 \%$ of total energy intake. The importance of dietary fat is emphasized in patients with CKD. In patients with DM, 
Table 3. Clinical blood biochemical analyses of the subjects according to kidney function

\begin{tabular}{|c|c|c|c|c|}
\hline \multirow{3}{*}{ Variable } & \multicolumn{4}{|c|}{ eGFR $\left(\mathrm{mL} / \mathrm{min} / 1.73 \mathrm{~m}^{2}\right)$} \\
\hline & \multicolumn{2}{|c|}{$\geq 60(n=17)$} & \multicolumn{2}{|c|}{$<60(\mathrm{n}=28)$} \\
\hline & Baseline & At 24 weeks & Baseline & At 24 weeks \\
\hline \multicolumn{5}{|l|}{ Biochemical data } \\
\hline Age (yr) & $56.0 \pm 12.5$ & & $61.1 \pm 12.2$ & \\
\hline Male sex & 9 (52.9) & & $10(35.7)$ & \\
\hline Diabetes mellitus & 7 (41.2) & & $15(53.6)$ & \\
\hline Systolic BP (mmHg) & $125.5 \pm 20.8$ & $120.4 \pm 9.1$ & $136.9 \pm 26.1$ & $126.7 \pm 22.5$ \\
\hline Diastolic BP (mmHg) & $71.0 \pm 9.7$ & $71.9 \pm 13.5$ & $73.6 \pm 14.9$ & $66.1 \pm 14.3^{\star, a}$ \\
\hline Calcium (mg/dL) & $9.3 \pm 0.5$ & $9.2 \pm 0.5$ & $9.3 \pm 0.5$ & $9.1 \pm 0.5$ \\
\hline Phosphorus (mg/dL) & $3.7 \pm 0.6$ & $3.7 \pm 0.5$ & $3.9 \pm 0.5$ & $3.8 \pm 0.6$ \\
\hline Glucose (mg/dL) & $122.9 \pm 34.9$ & $113.3 \pm 17.3$ & $124.4 \pm 32.8$ & $124.4 \pm 34.4$ \\
\hline $\mathrm{BUN}(\mathrm{mg} / \mathrm{dL})$ & $14.8 \pm 3.5$ & $15.3 \pm 5.6$ & $29.9 \pm 12.5^{\star, b}$ & $29.8 \pm 14.4$ \\
\hline Creatinine $(\mathrm{mg} / \mathrm{dL})$ & $0.9 \pm 0.2$ & $0.9 \pm 0.2$ & $1.9 \pm 0.7^{*, \mathrm{~b}}$ & $2.0 \pm 0.9$ \\
\hline $\operatorname{eGFR}\left(\mathrm{mL} / \mathrm{min} / 1.73 \mathrm{~m}^{2}\right)$ & $82.9 \pm 18.3$ & $84.5 \pm 22.9$ & $36.8 \pm 13.5^{*, b}$ & $35.7 \pm 15.6$ \\
\hline Cystatin C (mg/dL) & $1.3 \pm 0.5$ & $1.0 \pm 0.2$ & $2.0 \pm 0.7^{*, \mathrm{~b}}$ & $2.1 \pm 0.7$ \\
\hline Uric acid (mg/dL) & $6.0 \pm 1.3$ & $6.4 \pm 1.7$ & $7.0 \pm 2.0$ & $6.7 \pm 1.8$ \\
\hline Total cholesterol (mg/dL) & $226.2 \pm 8.4$ & $182.8 \pm 34.3$ & $221.3 \pm 38.8$ & $161.6 \pm 29.9^{*, a}$ \\
\hline Albumin $(g / d L)$ & $4.2 \pm 0.4$ & $4.3 \pm 0.3$ & $4.2 \pm 0.3$ & $4.3 \pm 0.4$ \\
\hline AST (U/L) & $30.3 \pm 10.5$ & $30.1 \pm 10.2$ & $25.8 \pm 11.1$ & $22.9 \pm 6.4$ \\
\hline $\operatorname{ALT}(\mathrm{U} / \mathrm{L})$ & $28.9 \pm 0.3$ & $28.9 \pm 13.6$ & $28.1 \pm 48.6$ & $18.5 \pm 9.1$ \\
\hline Triglycerides (mg/dL) & $192.1 \pm 139.4$ & $149.4 \pm 89.9$ & $181.7 \pm 93.1$ & $165.8 \pm 83.8$ \\
\hline HDL-cholesterol (mg/dL) & $54.8 \pm 19.9$ & $53.4 \pm 12.1$ & $47.0 \pm 16.8$ & $42.3 \pm 19.1$ \\
\hline LDL-cholesterol (mg/dL) & $154.4 \pm 45.8$ & $110.9 \pm 29.0^{*, a}$ & $145.8 \pm 27.2$ & $92.8 \pm 20.3^{*, a}$ \\
\hline $\mathrm{CRP}(\mathrm{mg} / \mathrm{dL})$ & $0.4 \pm 0.6$ & $0.1 \pm 0.1$ & $0.3 \pm 0.3$ & $0.2 \pm 0.2$ \\
\hline Urine protein $(\mathrm{g} / \mathrm{g})$ & $0.8 \pm 1.7$ & $1.3 \pm 4.3$ & $1.6 \pm 2.1$ & $1.7 \pm 3.1$ \\
\hline HbA1c (\%) & $6.2 \pm 1.0$ & $6.3 \pm 1.0$ & $6.7 \pm 1.0$ & $7.1 \pm 1.3$ \\
\hline Adiponectin ( $\mu \mathrm{g} / \mathrm{mL})$ & $8.2 \pm 4.9$ & $8.1 \pm 5.0$ & $9.1 \pm 3.9$ & $9.4 \pm 4.9$ \\
\hline \multicolumn{5}{|c|}{ Erythrocyte membrane fatty acid (\%) } \\
\hline Saturated & $40.7 \pm 2.0$ & $40.8 \pm 1.6$ & $40.3 \pm 0.8$ & $40.5 \pm 1.0^{*, a}$ \\
\hline Myristic & $0.4 \pm 0.1$ & $0.3 \pm 0.1$ & $0.3 \pm 0.1$ & $0.3 \pm 0.1$ \\
\hline Palmitic & $23.4 \pm 1.8$ & $23.1 \pm 1.4$ & $23.0 \pm 1.1$ & $22.9 \pm 1.2$ \\
\hline Stearic & $16.4 \pm 1.1$ & $16.9 \pm 1.4$ & $16.4 \pm 0.8$ & $16.8 \pm 0.8^{*, a}$ \\
\hline Lignoceric & $0.5 \pm 0.2$ & $0.4 \pm 0.1$ & $0.5 \pm 0.2$ & $0.4 \pm 0.1^{*, a}$ \\
\hline Monounsaturated & $15.8 \pm 1.2$ & $15.8 \pm 1.1$ & $15.9 \pm 1.1$ & $16.4 \pm 1.2^{*, a}$ \\
\hline Palmitoleic & $0.6 \pm 0.3$ & $0.5 \pm 0.2$ & $0.6 \pm 0.3$ & $0.5 \pm 0.3$ \\
\hline Trans-oleic & $0.3 \pm 0.1$ & $0.3 \pm 0.1$ & $0.3 \pm 0.2$ & $0.4 \pm 0.1$ \\
\hline Oleic & $14.7 \pm 1.1$ & $14.8 \pm 1.0$ & $14.8 \pm 0.9$ & $15.4 \pm 1.0^{*, a}$ \\
\hline Polyunsaturated & $42.7 \pm 2.7$ & $42.6 \pm 1.9$ & $42.9 \pm 1.0$ & $42.1 \pm 1.4^{*, a}$ \\
\hline Omega-6 & $28.3 \pm 2.8$ & $28.3 \pm 2.9$ & $29.4 \pm 3.1$ & $29.0 \pm 2.6$ \\
\hline Linoleic & $12.0 \pm 2.6$ & $11.0 \pm 2.2$ & $11.6 \pm 2.4$ & $10.6 \pm 2.2^{*, a}$ \\
\hline $\mathrm{AA}$ & $12.6 \pm 2.1$ & $13.4 \pm 1.9^{*, a}$ & $13.3 \pm 2.0$ & $13.7 \pm 1.9^{*, \mathrm{a}}$ \\
\hline Omega-3 & $14.3 \pm 2.9$ & $14.2 \pm 2.7$ & $13.5 \pm 2.9$ & $13.1 \pm 2.6$ \\
\hline Alpha-linolenic & $0.3 \pm 0.3$ & $0.2 \pm 0.1^{*, \mathrm{a}}$ & $0.3 \pm 0.2$ & $0.3 \pm 0.2$ \\
\hline EPA & $2.4 \pm 1.1$ & $2.3 \pm 1.0$ & $1.8 \pm 1.0$ & $1.6 \pm 0.9^{*, a}$ \\
\hline $\mathrm{DHA}$ & $8.9 \pm 1.6$ & $8.8 \pm 1.3$ & $8.8 \pm 1.8$ & $8.5 \pm 1.7$ \\
\hline Omega-3 index & $11.3 \pm 2.4$ & $11.1 \pm 2.2$ & $10.6 \pm 2.6$ & $10.1 \pm 2.3$ \\
\hline
\end{tabular}


Table 3. Continued

\begin{tabular}{|c|c|c|c|c|}
\hline \multirow{3}{*}{ Variable } & \multicolumn{4}{|c|}{ eGFR $\left(\mathrm{mL} / \mathrm{min} / 1.73 \mathrm{~m}^{2}\right)$} \\
\hline & \multicolumn{2}{|c|}{$\geq 60(n=17)$} & \multicolumn{2}{|c|}{$<60(n=28)$} \\
\hline & Baseline & At 24 weeks & Baseline & At 24 weeks \\
\hline AA/EPA & $6.7 \pm 4.0$ & $7.5 \pm 5.2$ & $11.6 \pm 11.3$ & $12.3 \pm 9.7$ \\
\hline Omega-6/omega-3 & $2.1 \pm 0.6$ & $2.1 \pm 0.6$ & $2.3 \pm 0.8$ & $2.3 \pm 0.7$ \\
\hline
\end{tabular}

Data are expressed as number only, or number (\%); erythrocyte membrane fatty acid content is expressed as a weight percentage of total fatty acid.

AA, arachidonic acid; ALT, alanine aminotransaminase; AST, aspartate aminotransferase; BP, blood pressure; BUN, blood urea nitrogen; CRP, C-reactive protein; DHA, docosahexaenoic acid; DM, diabetes mellitus; EPA, eicosapentaenoic acid; eGFR : estimated glomerular filtration rate; HbA1c, glycosylated hemoglobin; HDL-cholesterol, high-density lipoprotein cholesterol; LDL-cholesterol, low-density lipoprotein cholesterol.

${ }^{*} \mathrm{p}<0.05$; ${ }^{\mathrm{a}}$ mean values are significantly different from baseline; ${ }^{\mathrm{b}}$ mean values are significantly different from those of the GFR $\geq 60 \mathrm{~mL} / \mathrm{min} / 1.73 \mathrm{~m}{ }^{2}$ group.

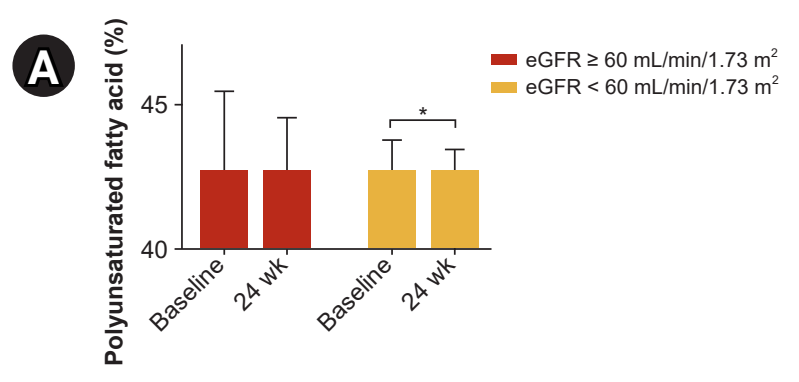

B
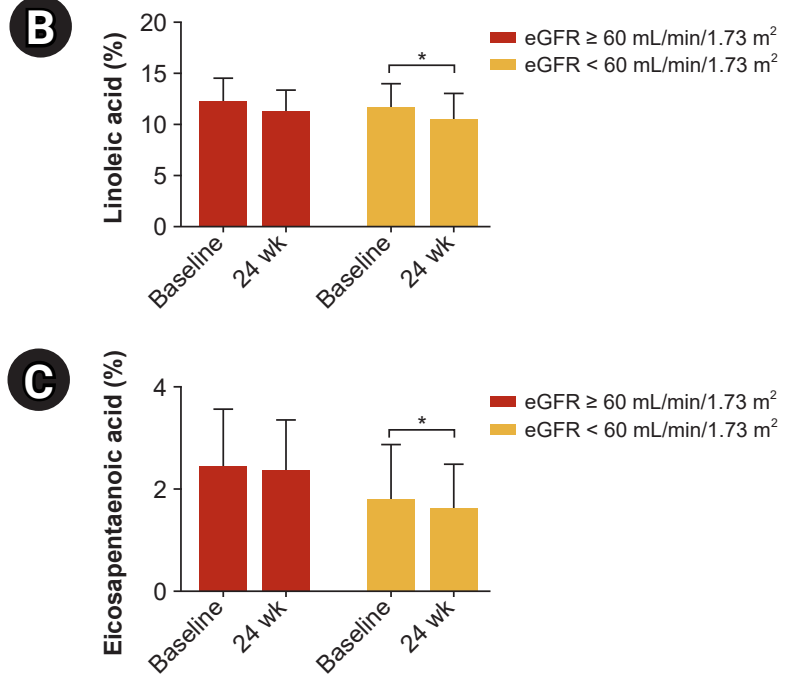

Figure 2. Changes of erythrocyte membrane fatty acid after pravastatin treatment according to kidney function. Bar graph shows the mean and standard deviation of fatty acid contents.(A) Polyunsaturated fatty acid, (B) linoleic acid, and (C) eicosapentaenoic acid in erythrocyte membrane. eGFR, estimated glomerular filtrate rate.

* $p<0.05$ (mean values are significantly different from baseline).

intake of greater SFA and lesser PUFA including LA is associated with progression of nephropathy $[27,28]$. A Mediterranean diet rich in foods containing omega-3 FA has reduced the incidence of CKD $[29,30]$. Changes in erythrocyte mem- brane FA, an indicator of FA status in the previous 3 months, have been linked to CKD. Changes in the contents of erythrocyte membrane FA are related to the poor prognosis of CKD or CVD. The mechanism of statin-induced erythrocyte membrane FA modulation is unknown. The erythrocyte membrane contains cholesterol, and changes in transmembrane cationic transport systems with statin use have resulted in alterations in erythrocyte membrane cholesterol content [31,32]. Coenzyme Q10 acts in the transmembrane electron transport system in the mitochondria and prevents lipid peroxidation during oxidative damage [33]. FA could increase bioavailability by increasing coenzyme Q10 absorption, and lack of FA could damage the enzyme activity in mitochondria [34]. Statins inhibit the production of coenzyme Q10 and could affect the structure of FA [35]. Negative pleiotropic effects of statins should be corrected by modification of erythrocyte membrane FA contents.

The current study has some limitations. First, clinical outcomes such as CVD development or mortality rate were not evaluated because of the short study period. Second, there was a relatively small sample size, high dropout rate in patients with eGFR of $>60 \mathrm{~mL} / \mathrm{min} / 1.73 \mathrm{~m}^{2}$, and no control group. To overcome these limitations, additional clinical studies with large sample sizes are required.

In conclusion, supplementations for PUFA, such as omega-3 FA or LA, might be necessary to recover erythrocyte membrane FA changes when pravastatin is used to treat dyslipidemia in patients with CKD. Further studies on reducing cardiovascular events using combined PUFA and pravastatin treatment are necessary.

\section{Conflicts of interest}

All authors have no conflicts of interest to declare. 


\section{Funding}

This study was supported by the Dong-A University Research Fund.

\section{Authors' contributions}

\author{
Conceptualization, Funding acquisition: WSA \\ Data curation, Methodology: SML, YHK, WSA \\ Formal analysis, Visualization: SML, WSA \\ Investigation: SML, YKS, SEK, YHK, YP, WSA \\ Project administration: SML, YKS, SEK, YHK, WSA \\ Writing-original draft: SML, WSA \\ Writing-review \& editing: All authors \\ All authors read and approved the final manuscript.
}

\section{ORCID}

Su Mi Lee, https://orcid.org/0000-0002-6455-8519

Young Ki Son, https://orcid.org/0000-0003-2197-1140

Seong Eun Kim, https://orcid.org/0000-0001-7133-6618

Yeong Hoon Kim, https://orcid.org/0000-0002-4101-9993

Yongsoon Park, https://orcid.org/0000-0001-5110-5716

Won Suk An, https://orcid.org/0000-0003-4015-0284

\section{References}

1. Tonelli M, Muntner P, Lloyd A, et al. Risk of coronary events in people with chronic kidney disease compared with those with diabetes: a population-level cohort study. Lancet 2012;380:807814.

2. Major RW, Cheng MR, Grant RA, et al. Cardiovascular disease risk factors in chronic kidney disease: a systematic review and meta-analysis. PLoS One 2018;13:e0192895.

3. Go AS, Chertow GM, Fan D, McCulloch CE, Hsu CY. Chronic kidney disease and the risks of death, cardiovascular events, and hospitalization. N EnglJ Med 2004;351:1296-1305.

4. Wanner C, Tonelli M; Kidney Disease: Improving Global Outcomes Lipid Guideline Development Work Group Members. KDIGO Clinical Practice Guideline for Lipid Management in CKD: summary of recommendation statements and clinical approach to the patient. Kidney Int 2014;85:1303-1309.

5. Zhao YY, Weir MA, Manno M, et al. New fibrate use and acute renal outcomes in elderly adults: a population-based study. Ann Intern Med 2012;156:560-569.
6. ACCORD Study Group; Ginsberg HN, Elam MB, et al. Effects of combination lipid therapy in type 2 diabetes mellitus. $N$ Engl J Med 2010;362:1563-1574.

7. AIM-HIGH Investigators; Boden WE, Probstfield JL, et al. Niacin in patients with low HDL cholesterol levels receiving intensive statin therapy. N Engl J Med 2011;365:2255-2267.

8. Gruppo Italiano per lo Studio della Sopravvivenza nell'Infarto miocardico. Dietary supplementation with $n-3$ polyunsaturated fatty acids and vitamin $\mathrm{E}$ after myocardial infarction: results of the GISSI-Prevenzione trial. Lancet 1999;354:447-455.

9. Lee SM, An WS. Cardioprotective effects of $\omega$-3 PUFAs in chronic kidney disease. Biomed Res Int 2013;2013:712949.

10. Kei A, Tellis C, Liberopoulos E, Tselepis A, Elisaf M. Effect of switch to the highest dose of rosuvastatin versus add-on-statin fenofibrate versus add-on-statin nicotinic acid/laropiprant on oxidative stress markers in patients with mixed dyslipidemia. Cardiovasc Ther 2014;32:139-146.

11. Wu NQ, Guo YL, Zhu CG, et al. Comparison of statin plus ezetimibe with double-dose statin on lipid profiles and inflammation markers. Lipids Health Dis 2018;17:265.

12. Dougherty RM, Galli C, Ferro-Luzzi A, Iacono JM. Lipid and phospholipid fatty acid composition of plasma, red blood cells, and platelets and how they are affected by dietary lipids: a study of normal subjects from Italy, Finland, and the USA. Am J Clin Nutr 1987;45:443-455.

13. Harris WS, Von Schacky C. The Omega-3 Index: a new risk factor for death from coronary heart disease? Prev Med 2004;39:212220.

14. An WS, Lee SM, Son YK, et al. Omega-3 fatty acid supplementation increases 1,25-dihydroxyvitamin D and fetuin-A levels in dialysis patients. Nutr Res 2012;32:495-502.

15. Lee SM, Chung SH, Park Y, et al. Effect of omega-3 fatty acid on the fatty acid content of the erythrocyte membrane and proteinuria in patients with diabetic nephropathy. Int J Endocrinol 2015;2015:208121.

16. Block RC, Harris WS, Reid KJ, Spertus JA. Omega-6 and trans fatty acids in blood cell membranes: a risk factor for acute coronary syndromes? Am Heart J 2008;156:1117-1123.

17. An WS, Kim SE, Kim KH, et al. Comparison of fatty acid contents of erythrocyte membrane in hemodialysis and peritoneal dialysis patients. J Ren Nutr 2009;19:267-274.

18. Leaf A, Kang JX, Xiao YF, Billman GE. Clinical prevention of sudden cardiac death by $n-3$ polyunsaturated fatty acids and mechanism of prevention of arrhythmias by n-3 fish oils. Circulation 2003;107:2646-2652. 
19. Kim OY, Lee SM, An WS. Impact of blood or erythrocyte membrane fatty acids for disease risk prediction: focusing on cardiovascular disease and chronic kidney disease. Nutrients 2018;10:1454.

20. Casula M, Mozzanica F, Scotti L, et al. Statin use and risk of new-onset diabetes: a meta-analysis of observational studies. Nutr Metab Cardiovasc Dis 2017;27:396-406.

21. Keech A, Colquhoun D, Best J, et al. Secondary prevention of cardiovascular events with long-term pravastatin in patients with diabetes or impaired fasting glucose: results from the LIPID trial. Diabetes Care 2003;26:2713-2721.

22. Miller ER 3rd, Juraschek SP, Anderson CA, et al. The effects of n-3 long-chain polyunsaturated fatty acid supplementation on biomarkers of kidney injury in adults with diabetes: results of the GO-FISH trial. Diabetes Care 2013;36:1462-1469.

23. Kalil RS, Wang JH, de Boer IH, et al. Effect of extended-release niacin on cardiovascular events and kidney function in chronic kidney disease: a post hoc analysis of the AIM-HIGH trial. Kidney Int 2015;87:1250-1257.

24. Harris WS. n-3 fatty acids and serum lipoproteins: human studies. Am J Clin Nutr 1997;65(5 Suppl):1645S-1654S.

25. Stone NJ, Robinson JG, Lichtenstein AH, et al. 2013 ACC/AHA guideline on the treatment of blood cholesterol to reduce atherosclerotic cardiovascular risk in adults: a report of the American College of Cardiology/American Heart Association Task Force on Practice Guidelines. Circulation 2014;129(25 Suppl 2):S1-S45.

26. Paik HY. Dietary reference intakes for Koreans (KDRIs). Asia Pac J Clin Nutr 2008;17 Suppl 2:416-419.

27. Cárdenas C, Bordiu E, Bagazgoitia J, Calle-Pascual AL; Diabetes and Nutrition Study Group; Spanish Diabetes Association. Polyunsaturated fatty acid consumption may play a role in the onset and regression of microalbuminuria in well- controlled type 1 and type 2 diabetic people: a 7-year, prospective, population-based, observational multicenter study. Diabetes Care 2004;27:1454-1457.

28. Dos Santos AL, Duarte CK, Santos M, et al. Low linolenic and linoleic acid consumption are associated with chronic kidney disease in patients with type 2 diabetes. PLoS One 2018;13:e0195249.

29. Khatri M, Moon YP, Scarmeas N, et al. The association between a Mediterranean-style diet and kidney function in the Northern Manhattan Study cohort. Clin J Am Soc Nephrol 2014;9:18681875.

30. Gopinath B, Harris DC, Flood VM, Burlutsky G, Mitchell P. Consumption of long-chain n-3 PUFA, $\alpha$-linolenic acid and fish is associated with the prevalence of chronic kidney disease. $\mathrm{Br} \mathrm{J}$ Nutr 2011;105:1361-1368.

31. Lijnen P, Echevaría-Vázquez D, Petrov V. Influence of cholesterol-lowering on plasma membrane lipids and function. Methods Find Exp Clin Pharmacol 1996;18:123-136.

32. Lange Y, Cohen CM, Poznansky MJ. Transmembrane movement of cholesterol in human erythrocytes. Proc Natl Acad Sci U S A 1977;74:1538-1542.

33. Niklowitz P, Menke T, Andler W, Okun JG. Simultaneous analysis of coenzyme Q10 in plasma, erythrocytes and platelets: comparison of the antioxidant level in blood cells and their environment in healthy children and after oral supplementation in adults. Clin Chim Acta 2004;342:219-226.

34. Tóth Š, Šajty M, Pekárová T, et al. Addition of omega-3 fatty acid and coenzyme Q10 to statin therapy in patients with combined dyslipidemia. J Basic Clin Physiol Pharmacol 2017;28:327-336.

35. Ghirlanda G, Oradei A, Manto A, et al. Evidence of plasma CoQ10-lowering effect by HMG-CoA reductase inhibitors: a double-blind, placebo-controlled study. J Clin Pharmacol 1993;33:226-229. 